\title{
Scalp Rotation Flap-Minor Changes Major Gains
}

\section{Dr. KN Manjunath*, Dr. MS Venkatesh and Dr. Karthik Vishwanath}

Department of Plastic \& Reconstructive surgery, Ramaiah Medical College, Bengaluru

\begin{abstract}
Introduction: Scalp plays an important role in individual's identity because of the hair at the same time it is prone for injury as it is exposed. Restoring a hairy scalp is a challenge. Rotation flaps are local option for medium defects reconstruction. However larger defects will need transposition flaps which leave big donor site defects. We modified the traditional method of rotation flap to cover large defects with either minimal or no donor site defect.
\end{abstract}

Materials and methods: 10 cases of scalp defects were operated with modification of rotation flaps.

Results: All flaps healed well. Donor site defect was completely closed or covered with minimal skin graft.

Conclusion: Minor changes in planning of rotation flap helped to cover large defects with less or no donor site defect.

Keywords: Scalp; Rotation flap; Reconstruction; Cosmetic; Trauma

\section{Introduction}

Scalp is unique structure, as it is hair bearing, has complex histology, and widely exposed. Because of these reasons scalp is susceptible to a multitude of neoplastic as well as inflammatory condition [1-3]. Scalp defects can arise following treatment of same and also following traumatic insults. The hair-bearing characteristics of the scalp and forehead being the cosmetic unit of face, reconstruction of scalp is challenging for all surgeons. The Rotation flap described is a good tool to close the medium sized defects without donor site defects [4]. However large defects cannot be closed by rotation flaps and need transposition flap which leave large alopecic donor site defects. Hence modified the traditional planning and elevation of rotation flaps so as to cover larger defects and could have minimal donor site defect [5]. So, the article is titled: "Scalp reconstruction with modified rotation flapminor changes major gains".

\section{Materials and Methods}

This study was conducted in the department of plastic and reconstructive surgery at our institute, Bangalore during the period of 2012 august to 2013 august with Total 10 cases.

Rotation flap is designed as follows:

\section{Modification}

The defect is triangulated (any shape but the widest will be the base of defect-ABC). Then the widest distance $A C$ is halved and projected onto distance $\mathrm{AC}$ (as $\mathrm{CD}$ ) and $\mathrm{BC}$ (as $\mathrm{BE})$. Then DE becomes the arc of rotation for the proposed modified rotation flap. The extra tongue of tissue between point $\mathrm{E}$ and point $\mathrm{A}$ is curved arbitrarily (Figure 1).

Modification-1: As the triangle is not isosceles the flap elevated with $\mathrm{DE}$ as the arc will not close the defect (i.e., point E won't meet point $\mathrm{A}$ ) hence the extra tongue (ABE) elevated by $\mathrm{DE}$ as the arc is utilised. Sometimes the tongue projects beyond the defect, such extra flap is utilised to fill in the gap created by incision along AF. This closes the defect completely and also breaks the straight line, to give clear contour for flap (Figures 2-3B).

Modification-2: Some of the defects the flap tongue (ABE), is utilised to close the defect by a U-turn onto the flap beyond marking DE. This flap was helpful in large defects (Figures 4-5B).

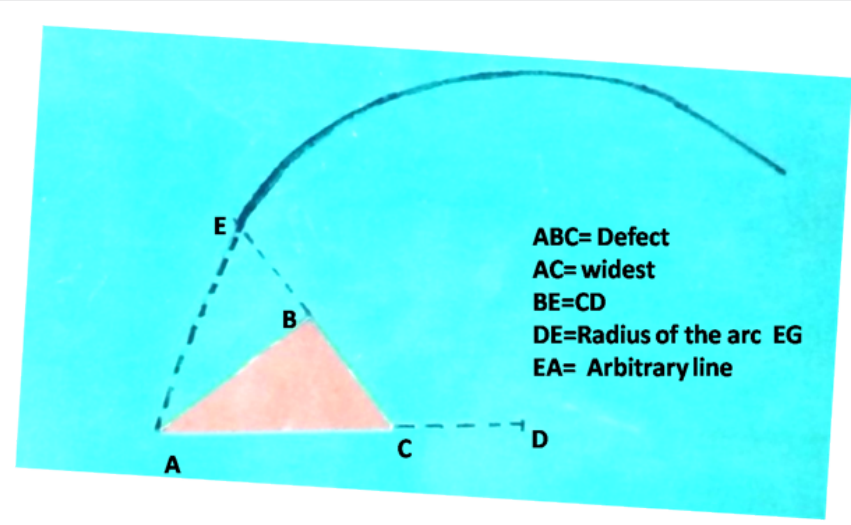

Figure 1: Flap design.

\section{Results}

Table 1 shows the patient details, the modification used and the flap status. Our 6 patients were male and 4 female. Majority of scalp defects originated because of trauma. The defects ranged between 5-12 $\mathrm{cms}$ (average $6.9 \mathrm{cms}$ ). Both modifications were used. Modification 2 was used in larger defects and 2 cases needed donor site skin grafts. No patients had flap necrosis or any complication. In modification -2, when tongue was rotated on itself there was dog ear near the closure. But this was very small and settled over the period.

\section{Discussion}

Scalp due to its exposed nature is affected own to by variety of insults like trauma, burns and infection [6]. The complex histology of scalp comprising of hair follicles, aponeurosis and fat can give rise to varied

${ }^{*}$ Corresponding author: Dr. KN Manjunath, Department of Plastic \& Reconstructive surgery, Ramaiah Medical College, MSR Nagar, MSRIT Post, Bengaluru 560054, Tel: 9535971056; E-mail: drknmanjunath@gmail.com

Received: May 02, 2017; Accepted: May 16, 2017; Published: May 22, 2017

Citation: Manjunath KN, Venkatesh MS, Vishwanath K (2017) Scalp Rotation Flap-Minor Changes Major Gains. Reconstructive Surgery and Anaplastology 6 : 166. doi: $10.4172 / 2161-1173.1000166$

Copyright: (c) 2017 Manjunath KN, et al. This is an open-access article istributed under the terms of the Creative Commons Attribution License, which permits unrestricted use, distribution, and reproduction in any medium, provided the original author and source are credited. 
Citation: Manjunath KN, Venkatesh MS, Vishwanath K (2017) Scalp Rotation Flap-Minor Changes Major Gains. Reconstructive Surgery and Anaplastology 6: 166. doi: 10.4172/2161-1173.1000166

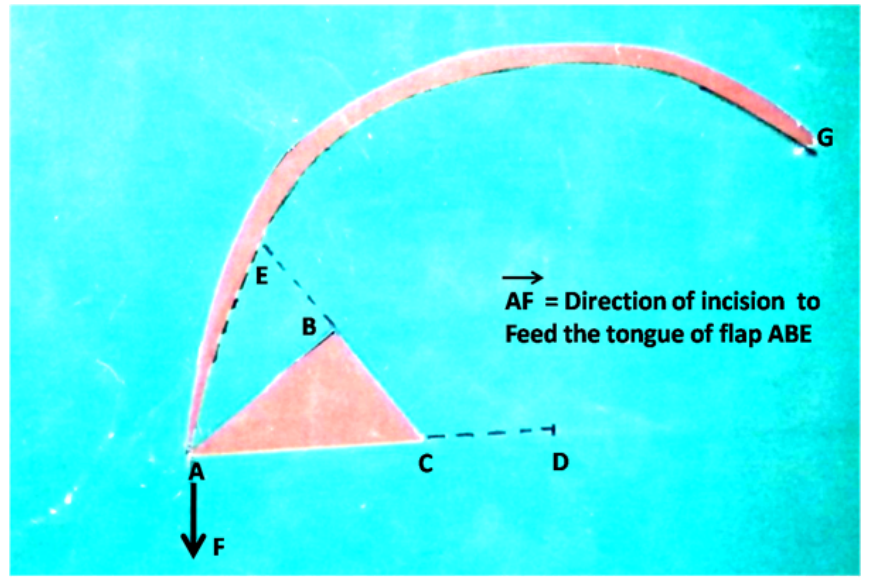

Figure 2: Incision direction to feed the tongue in modification 1.

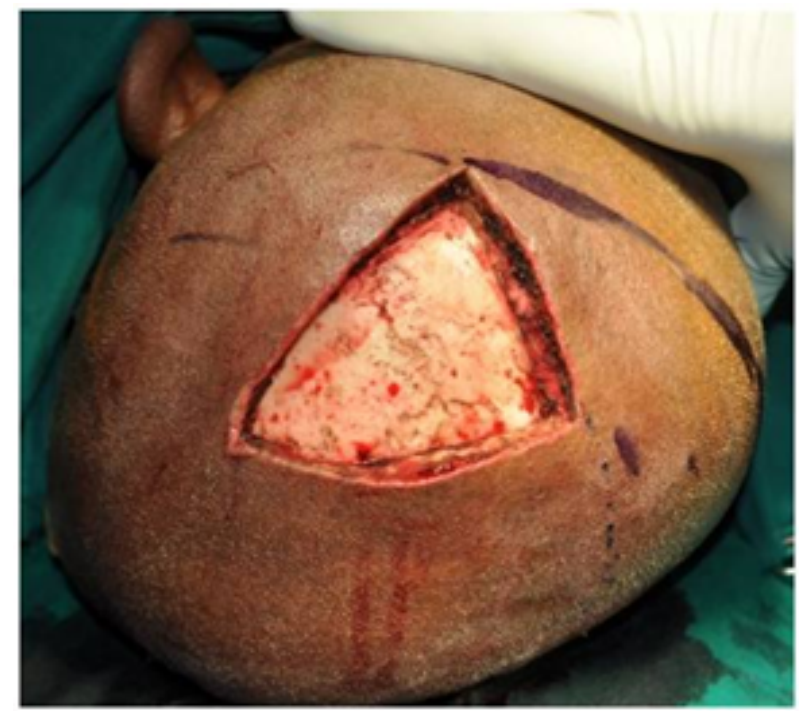

Figure 3A: Post excision triangular defect of scalp squammous cell tumor.

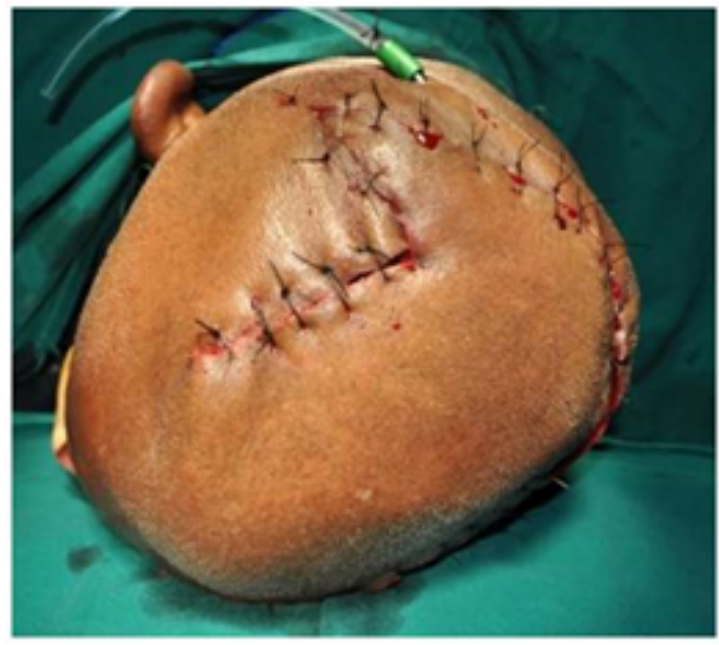

Figure 3B: After modification 1 rotation flap inset.

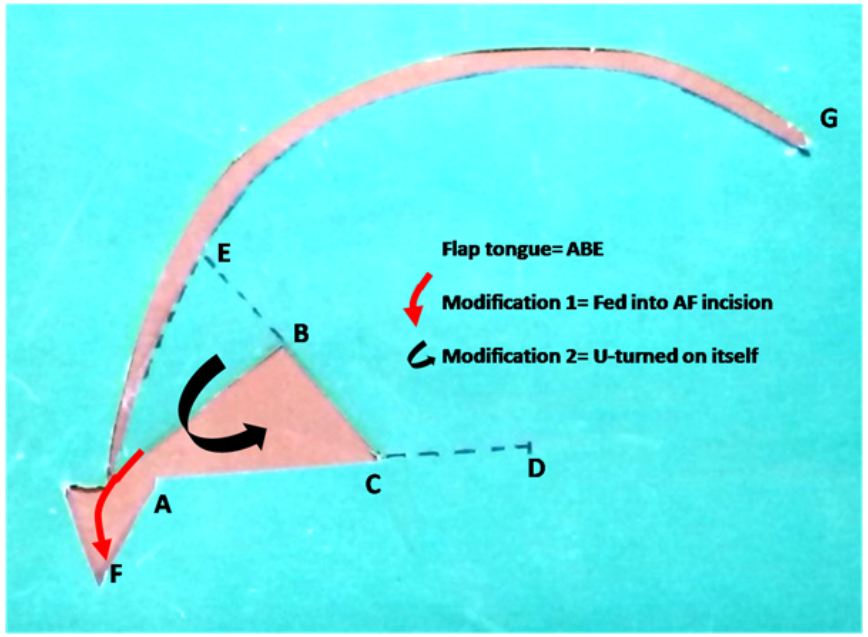

Figure 4: Direction of tongue of flap feeding in case of modification 1 and 2.

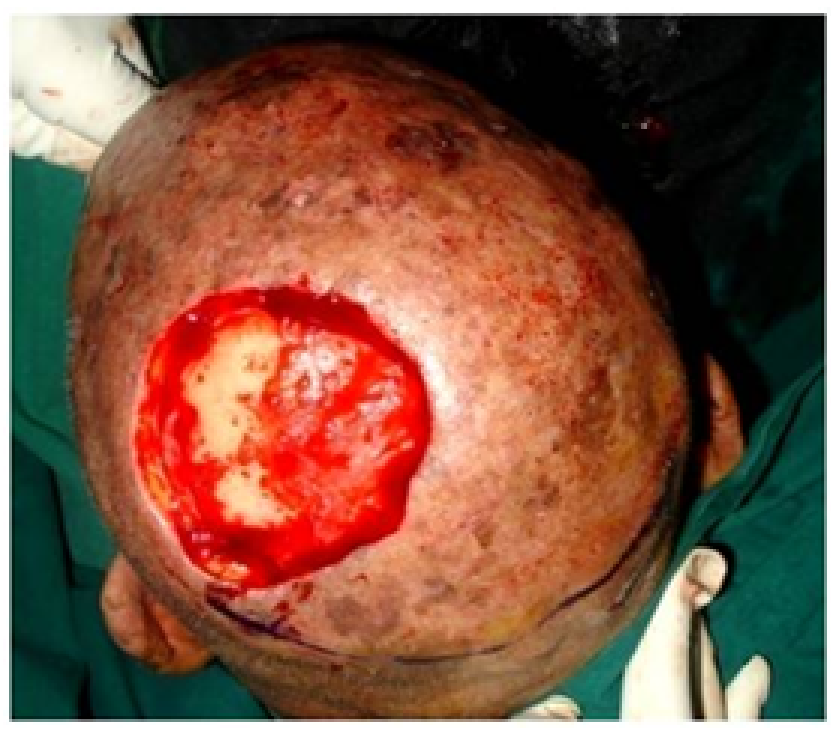

Figure 5A: Post traumatic scalp defect

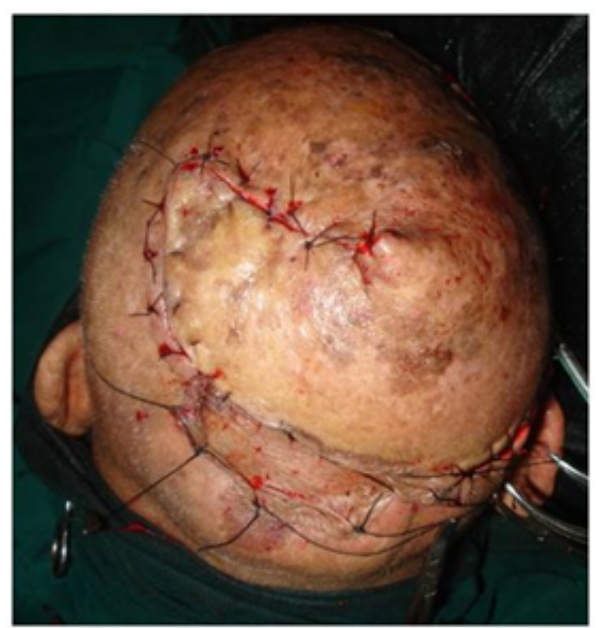

Figure 5B: After the inset of modification 2 rotation. 


\begin{tabular}{|c|c|c|c|c|c|}
\hline CASE & AGE & ETIOLOGY & $\begin{array}{l}\text { WIDEST } \\
\text { DIAMETER }\end{array}$ & FLAP* & RESULT \\
\hline $1 \mathrm{M}$ & $28 y$ & Trauma & $8 \mathrm{cms}$ & 1 & $\begin{array}{l}\text { No donor site } \\
\text { morbidity }\end{array}$ \\
\hline $2 m$ & $32 y$ & Trauma & $7 \mathrm{cms}$ & 1 & $\begin{array}{l}\text { No donor site } \\
\text { morbidity }\end{array}$ \\
\hline $3 \mathrm{M}$ & $45 y$ & $\begin{array}{l}\text { Squammous cell } \\
\text { carcinoma }\end{array}$ & $8 \mathrm{cms}$ & 1 & $\begin{array}{l}\text { No donor site } \\
\text { morbidity }\end{array}$ \\
\hline $4 \mathrm{M}$ & $68 y$ & $\begin{array}{l}\text { Basal cell } \\
\text { carcinoma }\end{array}$ & $5 \mathrm{cms}$ & 1 & $\begin{array}{l}\text { No donor site } \\
\text { morbidity }\end{array}$ \\
\hline $5 \mathrm{M}$ & $40 y$ & Trauma & $9 \mathrm{cms}$ & 2 & Minimal skin graft \\
\hline $6 \mathrm{M}$ & $54 y$ & Trauma & $12 \mathrm{cms}$ & 2 & Minimal skin graft \\
\hline $1 \mathrm{~F}$ & $34 y$ & Adnexal tumor & $7 \mathrm{cms}$ & 2 & $\begin{array}{l}\text { No donor site } \\
\text { morbidity }\end{array}$ \\
\hline $2 \mathrm{~F}$ & $48 y$ & $\begin{array}{l}\text { Squammous cell } \\
\text { carcinoma }\end{array}$ & $9 \mathrm{cms}$ & 2 & Minimal skin graft \\
\hline $3 \mathrm{~F}$ & $55 y$ & Trauma & $6 \mathrm{cms}$ & 1 & $\begin{array}{l}\text { No donor site } \\
\text { morbidity }\end{array}$ \\
\hline $4 \mathrm{~F}$ & $33 y$ & Trauma & $5 \mathrm{cms}$ & 1 & $\begin{array}{l}\text { No donor site } \\
\text { morbidity }\end{array}$ \\
\hline
\end{tabular}

${ }^{*}$ Flap 1-modification 1, Flap 2-modification 2

Table 1: Modification of flap status.

tumours both malignant and benign. Treatment of these conditions gives raise to various defects of scalp. The options to cover these are local or the distant flaps. The local flaps are always better option as they are compliant with Gilles principle-"replace like with like". However, when the defects are too large then free microvascularised flaps are the only option for scalp coverage. But, the long operative time, need of resources for these flaps is limitation. Hence, as for as possible, local tissues should be used for reconstruction of scalp $[7,8]$. Anatomically, scalp being highly vascular designing a flap and survival of flap is relatively better compared to other areas of body. But at the same time the tough Galea aponeurotica [9] and the convex nature of skull limits flap movement. Hence the design of flap is very much important as they should cover the defect and also have minimal donor site morbidity (alopecia). Rotation flaps are the one which cover the defect and also leave minimal donor site morbidity.

Rotation flap is designed as, standard rotation flap, modified rotation flap and divine rotation flap. All these design requires the defect to be triangulated as an isosceles triangle. As this triangle fits in the semicircle better, this prerequisite is must for all designs [10]. In our design the defect is triangulated as any acute angle triangle with base of triangle being the largest. Once the defect is triangulated, next is to determine the radius of the semicircular flap for elevation.

\section{Standard rotation flap}

Defect to triangular form (isosceles), with its apex $\mathrm{C}$ directed toward the base of the future pedicle of the flap (Figure 6). Apex C should be limited to an angle of 30 degrees to minimize "buckling" at this point after closure. Pivot point D will be located on a projection of line AC. Line CD must be at least 50\% longer than AC. Midway between A and $\mathrm{D}$, a point is designated, which becomes the centre for an arc drawn from $\mathrm{B}$ to $\mathrm{D}$ that completes the outline for the flap (Figure 6).

In this design the angle is fixed and base needs to be extended 11/2 times for elevation of whole circumference. In the design we propose the angle is any acute angle and hence triangle need not be isosceles.

\section{Divine rotation flap [11]}

\section{Calculate:}

(i) BC (ii) construct square BCDE (iii) Bisect DE- identify pivot

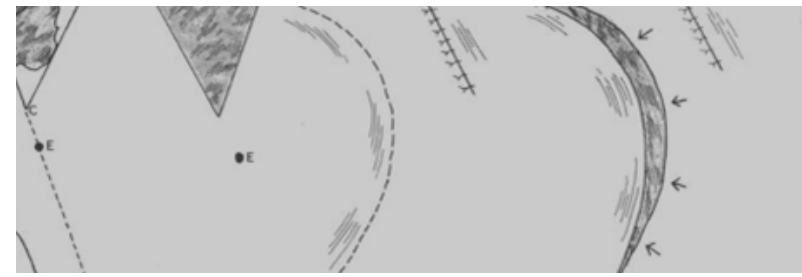

Figure 6: Design of standard rotation flap.

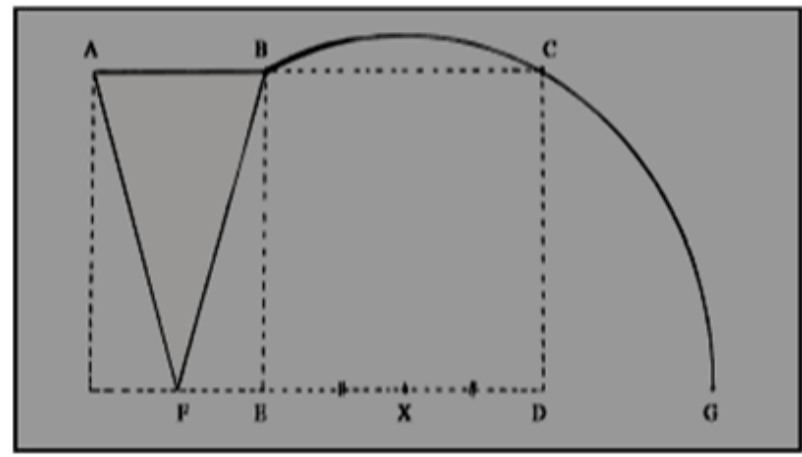

Figure 7: Design of divine rotation flap

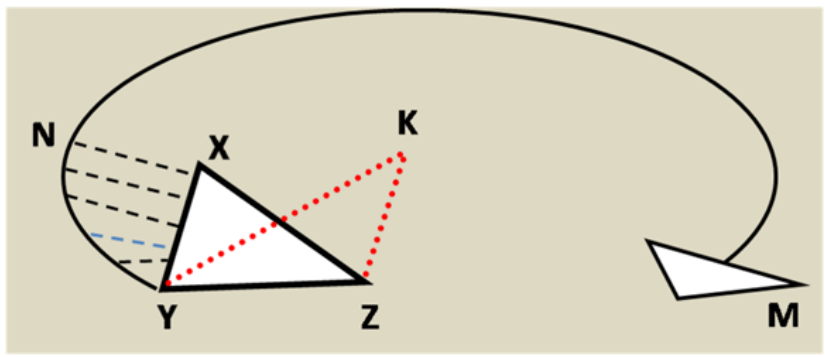

Figure 8: Design of modified rotation flap.

point $\mathrm{X}$ (iv) draw arc-BCG with radius $\mathrm{XB}$ (v) raise and rotate flap BCG (Figure 7).

As the depiction shows, this divine flap also needs the defect to be triangulated and calculation of the radius of the semi-circular flap needs complex calculation. In our modification flaps, the planning is easier and identifying the radius is also simple.

\section{Modified rotation flap [12]}

The modified rotation flap described makes the triangle isosceles (XYZ) and the radius (KY) is determined by making an limb parallel and equal $(\mathrm{XY}=\mathrm{KZ})$ to the base of the triangle and making the arc from distal most point $(\mathrm{Y})$. The arrow indicates the flap to be elevated (Figure 8). In the design we propose, identifying the radius is easier. The tongue of flap (NYX) elevated is discarded in modified rotation flap and the remaining flap rotated. This is against the popular principles of Gillies [13]. In our design of rotation flap also has tongue of flap elevated but not discarded. It is utilised to cover the raw area in larger defects. Some of the flaps it is fed in the back-cut given so that the tension is minimised and also the straight line of scar is also broken.

Cheng Hean Lo et al. [10] in his study showed that the tension in the flap is in initial rotation and by increasing the circumference of the flap was not useful in decreasing the tension. Using the same principle 
Citation: Manjunath KN, Venkatesh MS, Vishwanath K (2017) Scalp Rotation Flap-Minor Changes Major Gains. Reconstructive Surgery and Anaplastology 6: 166. doi: 10.4172/2161-1173.1000166

Page 4 of 4

we designed a flap which is more near to the defect and utilisation of the tongue of flap reduced the donor site morbidity and helped us to cover larger defects. Regarding the circumference of the flap, opinions differ as some say the circumference should be five to eight times $[14,15]$ and some authors opine that the edge of the flap should be flap four times [16] the base of the triangulated defect. If such parameters are included then the donor site should be very large, as the flap adjacent to defect is all that required in relieving the tension of closure, our design rotates the scalp adjacent to defect limiting the donor site morbidity. In some cases where modification was used, there was small dog ear near the U-turning of flap. This was however small and needed no further correction. Even other studies also are of similar opinion; the "dog ear" plasty is hardly required. If required, has to be done after some time as these tend to settle over period [9]. In cases where donor site could not be closed completely, skin graft was used to close the donor site. However, the graft used was very small and thus leaving a small area of alopecia. This area of skin graft could have been reduced if we had used Galeal scoring of the flap to increase the width of flap. These modifications cannot be used in flaps adjacent to non-hair bearing areas and in very large defects which would warrant free flaps.

\section{Conclusion}

Scalp is known to be affected by various etiological factors due to its exposed nature and complex histology. Reconstruction of large defects is challenging as tough scalp layers and convex nature of the skull limits movements. At the same time, rich vascularity of the scalp makes planning and elevation of the flap easier. Rotation flaps are well known reconstructive options for medium scalp defects. Coverage of large scalp defects would leave large donor site defect and unacceptable alopecia. Our Small modification in planning of the rotation flap helps to cover large defects with no or minimum donor defects. However, our experience is limited to 10 cases and further use of these modifications will help to know the nuances.

\section{Reference}

1. Frodel JL, Ahlstrom K (2004) Reconstruction of complex scalp defects: The "Banana peel" revisited. Arch Facial Plast Surg 6: 54-60.

2. Demir Z, Velidedeoglu H, Celebioglu $S$ (2003) V-Y plasty for scalp defects. Plast Reconstr Surg 112: 1054-1058.

3. Mehrotra S, Nanda V, Shar RK (2005) The islanded scalp flap: a better regional alternative to traditional flaps. Plast Reconstr Surg 116: 2039-2040.

4. Worthem EF (2005) Scalp flaps and forehead rotation flaps. Grabb's encyclopedia of flaps.

5. Ahuja RB (2008) Local flap template: present perfect tense or flap tense? J Plast Reconstr Aesthet Surg 61: 761.

6. Garcia del Campo JA, Garcia de Marcos JA, Castillo Pardo de Vera JLD, Jesus M, Marcos GD (2008) Local flap reconstruction of large scalp defects. Med Oral Patol Oral Cir Buccal 13: E666-E670.

7. Arnold PG, Rangarathnam CS (1982) Multiple-flap scalp reconstruction: Orticochea revisited. Plast Reconstr Surg 69: 605 - 613.

8. Chicarilli ZN, Ariyan S, Cuono CB (1986) "Single-stage repair of complex scalp and cranial defects with the free radial fore arm," Plastic and Reconstructive Surgery 77 : 577-585.

9. Leedy JE, Janis JE, Rohrich RJ (2003) Reconstruction of acquired scalp defects; an algorithimic approach. Plast Reconstr Surg 116: 54e-72e.

10. Lo CH, Kimble FW (2008) The ideal rotation flap: an experimental study. J Plast Reconstr Aesthet Surg 61: 754-761.

11. Sandhir RK (1997) Divine Rotation Flap. Ann Plast Surg 38: 194-195.

12. Ahuja RB (1989) Mechanics of movement for rotation flaps and a local flap template. Plast Reconstr Surg 83: 733-737.

13. Gillies H, Millard Jr. (1957) The principles \& art of plastic surgery (1st edn) Butterworth \& Co Ltd., London.

14. Richards AM (2002) Plasty techniques. In: Key Notes in Plastic Surgery. Blackwell Science Itd, Oxford. p. 13.

15. Daniel RK, Kerrigan CL (1990) Principles \& physiology of skin flap surgery.

16. Jankauskas, Cohen IK, Grabb WC (1991) Basic techniques of plastic surgery. In: Smith JW, Aston SJ (eds.). Grabb \& Smith's Plastic Surgery (4th edn.) Little, Brown and Company, Boston. 